\title{
Research on the Evaluation of Carbon-Intangible Assets in Business Based on Internal Value Network
}

\author{
Yuguo Jiang, Lili Fan, Yanxi Yu, Genghong Shi \\ School of Economics and Management, Southwest Jiaotong University, Chengdu, China \\ Email: daocaoren2007@126.com
}

Received 25 September 2014; revised 20 October 2014; accepted 7 November 2014

Copyright (C) 2014 by authors and Scientific Research Publishing Inc.

This work is licensed under the Creative Commons Attribution International License (CC BY). http://creativecommons.org/licenses/by/4.0/

(c) (i) Open Access

\begin{abstract}
In recent years, under a low carbon economy and an effective energy saving situation developing enterprises, managing development and improving low carbon competitiveness have become a major problem facing modern enterprise. Firstly, we describe the meaning and range of carbonintangible assets and then classify and evaluate it. Secondly, we discuss the problem of evaluating enterprise carbon-intangible assets from the perspective of an internal value network, providing some ways to cultivate more carbon-intangible assets of industrial enterprises.
\end{abstract}

\section{Keywords}

Internal Value Network, Carbon-Asset, Carbon-Intangible Asset

\section{Introduction}

As global temperatures continue to rise, the human environment has deteriorated sharply. Greenhouse gas emissions due to human activities are the main contributors to global climate change, the problem should not be ignored. French and British-led countries proposed the model of low carbon economy. Facing severe environmental crisis, more countries are gravitating to this model naturally. The efforts of international communities to battle global warming are evident in the establishment of the United Nations Framework Convention on Climate Change (UNFCCC). This international treaty, signed by most countries, entered into force in March 1994, and established the basic framework for international cooperation on climate change. The Kyoto Protocol (KP), an international agreement ratified by a near-universal membership of 193 Parties linked to the UNFCCC, was adopted in December 1997 to bind greenhouse gas (GHG) emissions reduction targets for 37 industrialized countries and the European Community. After that, the international voluntary market for carbon credits under the system operated by the Clean Development Mechanism (CDM) developed rapidly. According to statistics 
from 2013, the number of carbon emissions traded has increased to 10.42 billion tons, and the total amount of transactions is approximately $\$ 54.98$ billion. It has increased to $\$ 88.70$ billion in 2014 . We can see the model of low-carbon development has become the general trend for industrial enterprises. The emphasis on a low carbon economy has increased the importance of the management of the Carbon-intangible assets. How to manage the Carbon-intangible assets has become an important question that key decision makers have to face.

As a microcosmic body of the national economy, industrial enterprise is directly related to the implementation of the strategy of sustainable development. However, most industrial enterprises don't know how to answer the following questions. How to evaluate low carbon competitiveness? Which economic indicators can we use to evaluate competitiveness of a company on the low carbon market and its turnover compared to other companies? How to analyze the development trend? How to find their own shortcomings? In this paper, we use the enterprise value network to discuss the evaluation of Carbon-intangible assets.

\section{Definition of Relevant Concepts and Research Status}

\subsection{The Carbon-Intangible Assets}

Originally, there has been no idea of Carbon-intangible in the world. It is neither a commodity, nor an economic conception. After the signing of the Kyoto Protocol, under the programming of the reasonable environment capacity, the concept of carbon assets comes out from the limitation of the greenhouse gas emissions by the politicians [1]. At present, there is no unified conclusion about the connotation of the carbon asset in theory. Wang Jianxin (2011) the chief representative of Chicago Climate Exchange (CCX) believes that the carbon assets are kinds of tangible assets or intangible assets in the field of low carbon that can be applicable to the storage, circulation or wealth transformation. Lin Hui (2009) argues that the carbon assets are tangible and intangible assets with potential value in application in the field of low-carbon economy, which can be applicable to the storage, circulation or wealth transformation [2]. Zhang Peng (2011) thinks that carbon asset is a kind of environmental resources that was artificial separated by the establishment of the relevant system and owned (or controlled) by industrial enterprises. And carbon assets are consumed with the discharges of companies on greenhouse gas emissions [3]. Wan Lin Wei (2010) thinks carbon asset refers to the resources that can bring economic benefits to the enterprises, and this resource is a balance of lower greenhouse gas discharged by enterprises than the official regulations after the implementation of emission reduction projects [4]. Takashi Kanamura (2012) summarizes the qualitative characteristics of carbon assets, including native carbon assets and derivative assets, and tries to explain the differences between carbon futures prices and energy futures prices [5]. Warwick (2012) Carbon asset is a kind of carbon credits, according to the environmental objectives, the government set a certain period in advance total greenhouse gas emissions limits, and then according to the status of the enterprise or industry determine the emission reductions of the enterprise or industry, refined to each enterprise, as an enterprise allows emissions of greenhouse gases during the period, it is the enterprise carbon asset [6]. Above all, the understanding of carbon assets have a common point: it has a contribution to a low carbon environmental protection and economy.

Carbon assets can be divided into carbon-tangible assets and carbon-intangible assets [7]. Carbon-tangible assets contain low carbon buildings or equipment etc., and its value can be accurately calculated and evaluated. Carbon-intangible assets are kinds of intangible properties in low-carbon activities, which not only brought economic benefits to the enterprise, but also made contributions to the Low-Carbon Economy. For instance, the development strategies, conducts, technologies and organizations under the low-carbon economy could promote enterprises to reduce carbon emissions. The government's carbon quotas and the participation in CDM projects will improve the image of the enterprise and promote social development. The value is not easy to be determined, and more difficult to be quantitative. The low-carbon development way will encourage company reform to reduce energy consumption and carbon emissions. They play a strong role invisibly in promoting the environment and economy. As a kind of intangible property, the carbon-intangible assets have no physical form. It is identifiable but non-monetary. In addition, carbon-intangible asset also has other characteristics like scarce, global, common benefited, investable and can be over drafted [7].

\subsection{Internal Value Network}

In reality, the enterprises had been living in a value network which was composed of the various stakeholders. 
As a member of it, a company has great independence and difference between the other entities. The essence of the value network is exist on the premise of making full use of specialization, through the value of the related transmission mechanism, the stakeholders and their individual departments in the value network work together to create value for customers. Adrian Slywotzky (1998) proposed the concept of The Value Network in his book "Profit zone" for the first time. He pointed out that The Value Network is a new business model that will connect the customers increasingly demanding requirements and flexible, efficient, low-cost manufacturing. Adopting digital information fast delivery products, to avoid the high distribution agent layer. Put the cooperation of providers together, in order to deliver customized solutions, to raise its rates to a strategic level, and to adapt to the constantly changing. The concept of enterprise value appears in the book "Co-opetition” (Adam Brandenburger and Barry Nalebuff, 1996). This book emphasizes the following two concepts, win-win cooperation and the corporate symbiosis.

Previous studies about the value network are always involved in the value between companies, suppliers and the customers, and rarely directly related to the business stakeholders, and will not involve the internal value network. In fact, there is a value network within the enterprise, and this network is more complex than the external value network, which involves various departments within the enterprise, and it interacts with the external value network and supports the development of enterprises together. Zhao Mingjian (2004) considers the internal value network is the network value judgment by people posed [8]. The internal value network is made up of a set of elements such as the corporate culture, business philosophy, human resources, organization, coordination, and other elements in the body with unity and creativity. This power with the value of the enterprise and established processes reflect a new standard of it.

\subsection{Research Status}

Now, the literature to the evaluation of intangible assets is less. Fan Lili (2010) from the perspective of core competitiveness of enterprises conducted a systematic review of carbon intangible assets [9]; Zhang Zhenling (2007) study the ability of intangible assets of enterprises from the view of core competitiveness [10]. There is few literature related to carbon-intangible assets' evaluation. In this paper, we study the carbon-intangible assets from the view of enterprise internal value network.

Values within the enterprise network influence factors include two aspects of "soft" and "hard" [7]. "Soft" aspects involving employees concept, corporate culture, etc., the "hard” mainly includes organization structure, technology promotion, etc. From the general point of view, the formation of enterprise value network is mainly influenced by three aspects: technical standards, organization optimization and process improvement. In the internal value network of the enterprise, the definition and value of the carbon intangible assets is determined by the contribution of this intangible asset to the energy conservation and emissions reduction. Enterprises Obtain carbon intangible assets based on the "credit” basis. And enterprises obtain technology improvement, organization optimization and process improvement through the internal value network, so as to reduce greenhouse gas emissions, and then promote the low carbon competitiveness of the enterprises, and accumulate more carbon intangible assets.

\section{Evaluation of Corporates' Carbon-Intangible Assets Based on the Internal Value Network}

In order to explore business potential carbon intangible assets, this article uses the indicators about "soft” and “hard” to evaluate the carbon intangible assets which were presented by Zhao Mingjian in 2004.

\subsection{The Classification of Carbon-Intangible Assets Based on the Internal Value Network}

Every enterprise has an internal value network structure, in the first stage it formed in the game between enterprises, that value network is an internal contract which has the deepest influence on enterprises. The standard contract formation is weighted to maximize the value of each player; this process may be referred to the process of the formation of the internal value network.

Factors affecting the formation of carbon-intangible assets involved employees concept, corporate culture, organization structure, technology, human resources, intellectual property, process improvement, etc. Generally speaking, the factors affecting carbon-intangible assets include three aspects under internal value network. 


\section{1) Technical Standard}

Level of Technology is not only the enterprise premise to improve the yield and the quality of products, but also a prerequisite for the enterprise energy-saving emission reduction. With the improvement of carbon technologies, relevant technical standards would contribute to kind of carbon intangible assets. These kind carbon intangible assets include intellectual property, proprietary technologies, such as CCS technology. Enterprises need to have strong learning ability and strong executive ability to formulate and implement a low carbon technology standard. Formulation and implementation of low-carbon technology standard can promote the establishment of an internal value network of the carbon-intangible assets. Only enterprises with advanced low-carbon technologies, the organization can strictly implement the relevant plans, and the carbon-intangible assets in the enterprise internal value network will continue to be accumulated, stored, and circulated.

2) Organization Optimization

A scientific program needs to have a high efficient organization and coordination mechanism to cooperate, and design the organizational structure on the basis of complete enterprise production plan needs. In the internal value network, enterprise organization structure and carbon value of intangible assets have close connection, laid the foundation for the formation of carbon-intangible assets, such as low carbon supervision departments, organizations and emission reduction mechanism, departments and job responsibilities, emission reduction. In this context, the concept of low carbon, technology, and standards have been effectively communicated. This kind of intangible assets mainly include carbon system culture, spiritual culture which related to the low carbon, low-carbon technology, human resources, low-carbon organization and coordination mechanism, etc.

3) Process Improvement

Processes are related to the enterprise internal value network and orientation of it. Reasonable process design is the fundamental element of enterprise energy conservation and emissions reduction, and it is also an important way to produce carbon-intangible assets. Business process management involves many aspects, with the expansion of business scale, the evolution process from the original single department operation for the integration of across the organization. The value of carbon-intangible assets embodied in the internal value network needs to break the original process. The enterprise needs to make some improvement on the basis of the original process. Carbon-intangible assets produced by process improvement mainly includes in the production process. Through the process of innovation, such as process, shorten and combinations, the companies reduce the emissions of greenhouse gases.

According to internal influence factors of carbon-intangible value network, our enterprise internal carbon-intangible assets can be divided into three categories: produced by technical standards, organization optimization, and produced in process improvement.

\subsection{Research on Evaluation of the Carbon-Intangible Assets in Business Based on Internal Value Network}

Carbon-intangible assets should be a system, the value can not use the simple addition of single carbon-intangible assets value. They should be organic combination. Under this thought, we firstly design a space system which divided the internal carbon-intangible assets into three main categories. Due to some of the carbon-intangible assets may be between two or three categories to reflect their value, we will place some parts of the carbon-intangible assets within the space coordinate system instead of axes. We will quantify the value of each branch of the internal value network through multiple dimensions, then to calculate the value produced by each branch.

According to the analysis found that the amount of value created by carbon-intangible assets in an enterprise could be evaluated by the degree of development and utilization of the carbon-intangible assets, the degree of imitation and whether the intangible-assets can continuing to create value for enterprises [9]. According to above analysis, we will be in the space of three dimensions ( $\mathrm{X}, \mathrm{Y}$ and $\mathrm{Z}$ axis) to evaluate the value of carbon-intangible assets. This study was conducted as follows:

1) Companies have a number of types of carbon-intangible assets based on the internal value network, but in the aggregate, there are mainly three categories: technical standard, organization structure, and the innovation process. Therefore, distinguishing the categories of carbon-intangible assets within the enterprise network value is the premise of value judgment.

2) Develop a carbon-intangible assets evaluation index system. The index system mainly includes all kinds of 
carbon-intangible assets in various dimensions of evaluation indexes and its weight, all kinds of intangible assets in the whole weight, etc. The quality of the index system directly affects the objectivity of evaluation results. In order to ensure the scientific nature of the evaluation index system, we should use rigorous and scientific methods in the process of index design.

3) Accurately collect the relevant data. Research needs to collect data needed in build index system, and we should ensure the collection process objective, comprehensive, truthful and reliable. Objective and comprehensive data is a prerequisite for scientific evaluation.

4) Research located each carbon-intangible assets based on the data obtained. According to the relevant index system and data collected, we are able to locate the value of each carbon-intangible asset in three-dimensional value space.

5) After positioning carbon-intangible assets and comparing with the same industry advanced level, the value of each enterprise's various carbon-intangible assets will have a corresponding point in the value space, and these points can form a kind of regional distribution. We integrate the value structure of the carbon-intangible assets (such as Weighted Vector Sum). On the one hand, we can get the spatial value of carbon-intangible asset in enterprise A; on the other hand it can be compared with enterprise B which has the advanced level in the same industry. Finally it is concluded the value of an enterprise's potential carbon-intangible assets.

Company's carbon-intangible assets can promote the low carbon competitiveness of it. Of course, different type of carbon-intangible assets contribution to the competitiveness of the angle and the size are different. Some of the carbon-intangible assets have a higher practical value, some with strong sustainable returns, some with no imitability, and some with all the above characteristics. In order to determine the competitiveness of the enterprise's carbon intangible assets from various angles for convenience. Article adopts the method of "multidimensional evaluation space", establishing evaluation system from multiple perspectives to assess the business carbon-intangible assets. And use it to systematically evaluate the value of all kinds of carbon-intangible assets, and the contribution to the low carbon competitiveness [7]. Assuming carbon-intangible assets about enterprise's technology standard include 8 classes. A1, A2, A3, A4, A5, A6, A7, A8 can be evaluated according to the three dimensions; we can get all kinds of carbon -intangible assets in the spatial distribution of enterprise A, as shown in Figure 1.

We assume that the carbon-intangible assets about organizational structure in enterprise A have four types: B1, B2, B3, B4, assets produced in the process of innovation is C1, C2, C3. They all can be evaluated and location according to the three dimension. And the result of the three kinds of value added will be reflected in the internal carbon intangible assets of the enterprise. We obtained three types of value orientation in space, in Figure 2.

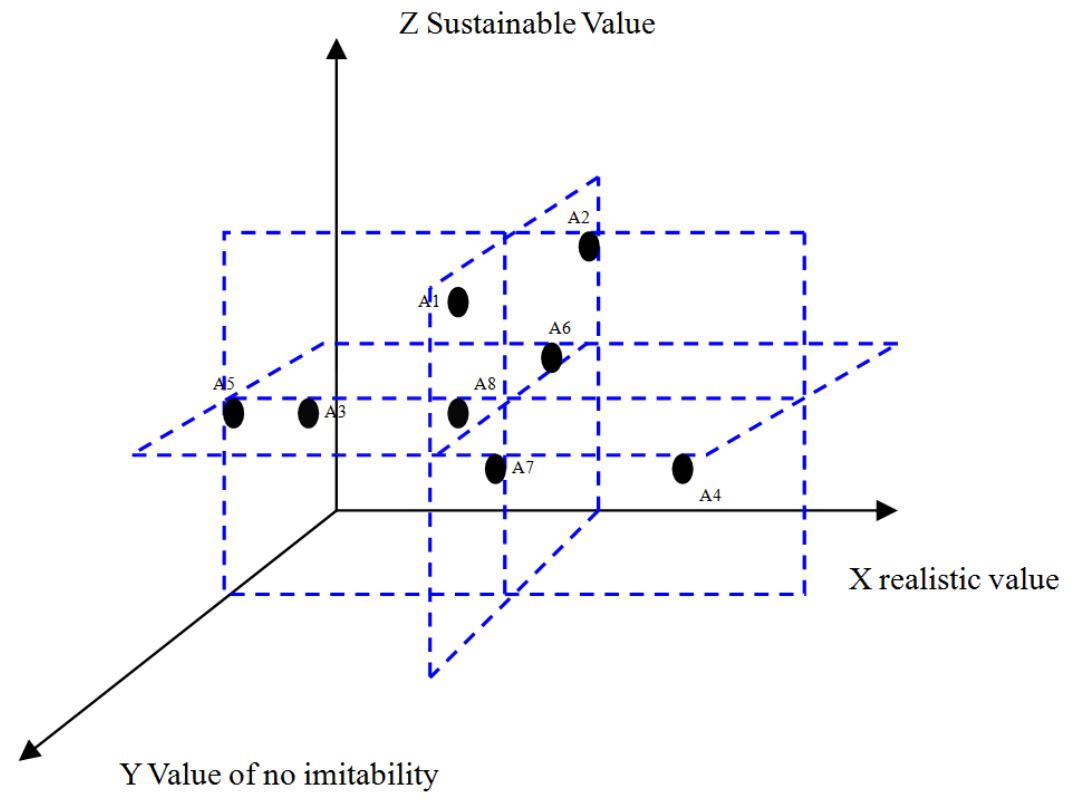

Figure 1. Spatial distribution of carbon-intangible assets produced by technology standards. 


\section{Z Sustainable Value}

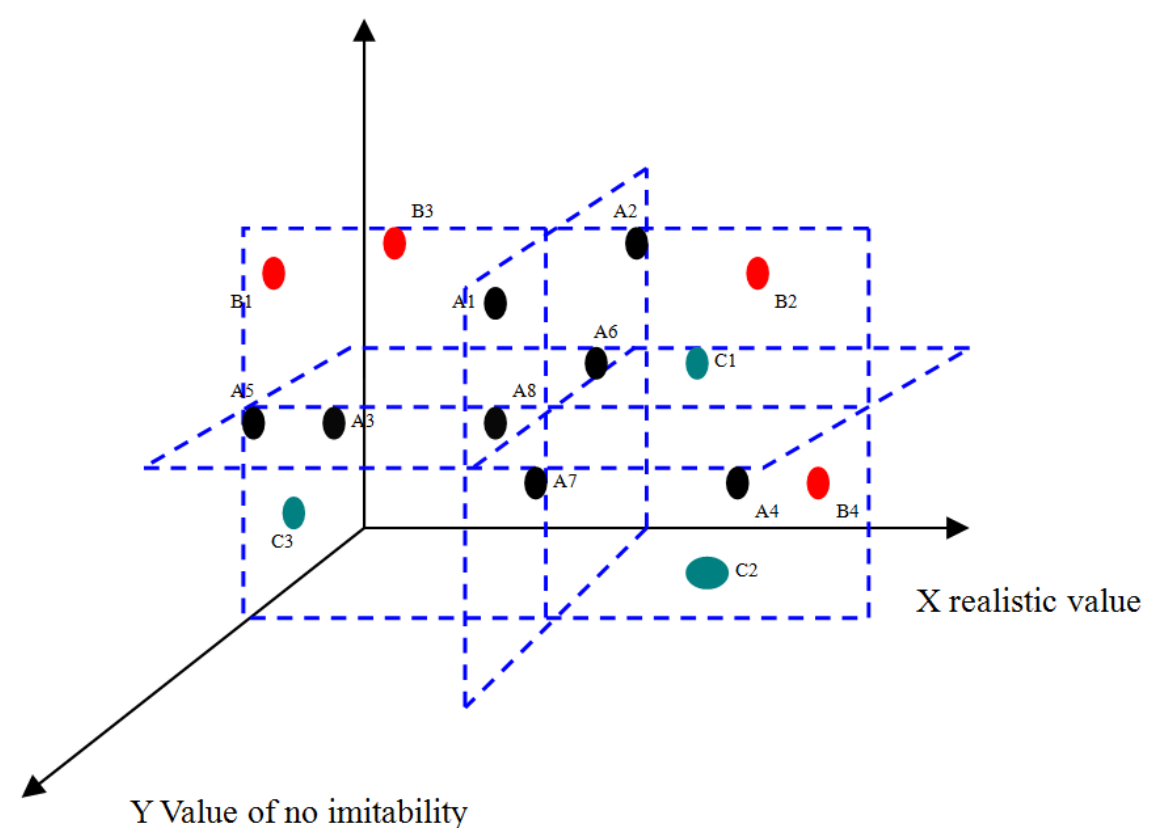

Figure 2. Spatial distribution of three kinds of carbon-intangible assets in enterprise A.

The distribution of various points of three kinds of carbon-intangible assets in corresponding evaluation space, constitutes the enterprise overall carbon-intangible assets energy trend, this trend will continue to reflect the low carbon competitiveness of enterprises in a fairly long period of time [9]. We often use the weighted average method, synthesis the various assets in Figure 2, then come to a low-carbon competitiveness of enterprises, thus with the advanced level of the B companies compare in Figure 3.

Assuming the external environment and the technical level there are no major changes. We compare these three kinds of assets with the advanced object in the same industry, and then concluded that enterprise's potential competitiveness of low carbon. Of course, we also can build other n-dimensional spatial assessment to evaluate the value of the carbon-intangible assets. The evaluation results can provide decision reference for decision-makers in the company.

\section{Conclusions and Suggestions}

Along with the deepening of the research on carbon-intangible assets, the angle of it will continue to expand. Carbon-intangible asset is a kind of asset based on political constraints. Enterprises can get quota from outside project, so as to obtain maintain in a short period. But from the low carbon competitiveness of enterprises for a long time, the fundamental way is to enhance the internal value of low carbon.

Carbon-intangible assets as a new type of assets, how to effectively identify, develop, cultivate, manage, and enhance its value, is a new problem in front of each enterprise. The management of carbon-intangible assets is both an opportunity and a challenge. By controlling various aspects of the internal value of the network, the company makes the value of carbon-intangible assets to maximize, enhancing the competitiveness of enterprises, and obtaining the corresponding benefits. Based on the above analysis, companies need to follow these three aspects, so as to make profit from the asset management.

1) Improving the organizational structure of the enterprise. Enterprises should vigorously promote low-carbon culture in its interior, promote low carbon concept, training some related knowledge, and create a low-carbon atmosphere; Put the carbon assets into the financial system, and make "the carbon inventory accounting". Encouraged to join carbon reduction items in the balance sheet, and then promote the recognition about the concept of carbon-intangible assets and liability principle. We should set up production supervision agencies, the agency responsible for the supervision of the $\mathrm{CO}_{2}$ emissions, need to make division of various departments' responsibility for emissions reductions. All departments need to evaluate their own emission reduction effect, and the re- 


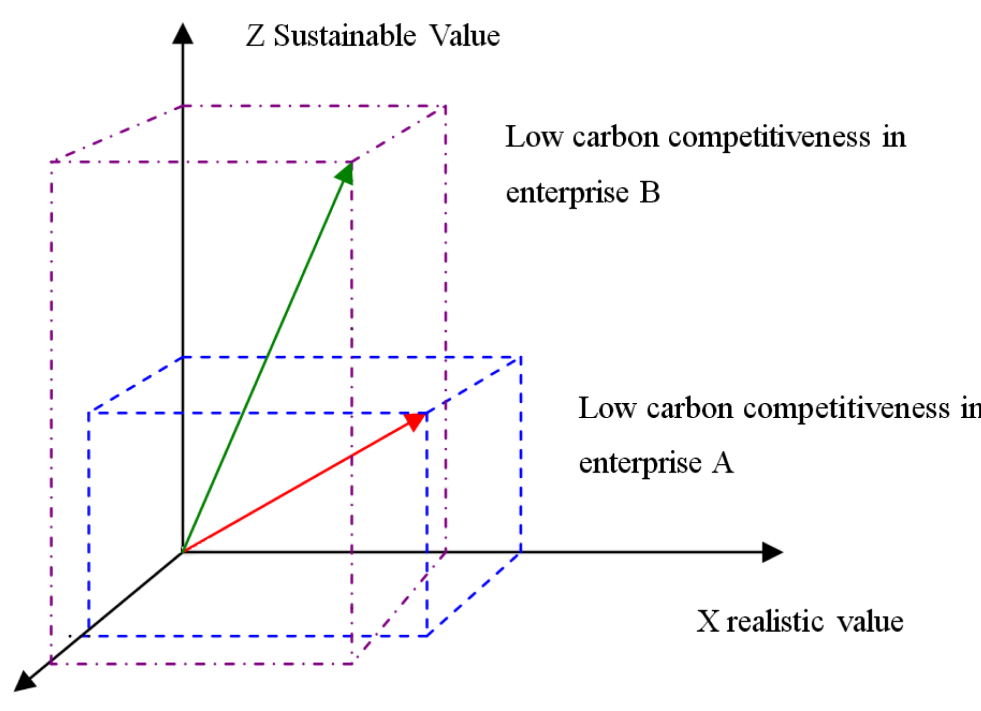

Y Value of no imitability

Figure 3. Compare of three kinds of carbon-intangible assets in enterprise A and advanced standard B.

duction results into the performance evaluation system. Taking the initiative to develop low-carbon development strategies, and put the low carbon planning to a strategic level [7].

2) Setting reasonable technical standards. We should develop related technical specifications and standards in Company. At the same time, formulate a reasonable operating rules and procedures, in order to promote the cultivation of carbon-intangible assets [11]. Based on their technical characteristics, we gradually update energy supply, use more clean energies, and reduce the proportion of the use of fossil fuels. For some large enterprises with research and development ability, investment in research and development funds can be enhanced according to its industry characteristics to obtain intellectual property, proprietary technology, copyright and other intangible assets.

3) Establishing innovation process. The innovation process is the basic elements for the energy-saving emission reduction of the internal value; it is also an important way to produce carbon-intangible assets. It reflects the enterprise's profit distribution, standard form, value orientation and the organizational structure of the enterprise, etc. Processes need to be improved vary from enterprises to enterprises. But as long as the improving process is good to low carbon, we can think that the process creates carbon-intangible assets. In the process of production, we reduce $\mathrm{CO}_{2}$ emissions by improving the production process, repeated adjusting production, gradually optimized production process and so on.

\section{Funding}

Funded by the national natural fund project "Research on Systematic evaluation of enterprise low carbon competitiveness in the perspective of carbon-intangible assets" (71271177).

\section{References}

[1] Hepburn, C. (2007) Carbon Trading: A Review of the Kyoto Mechanisms. Environment and Resources, 11, $375-393$.

[2] Lin, H. (2009) Under the Trend of Low Carbon Enterprise Competition in the Future. Journal of Sales and Marketing, 11, 36-39.

[3] Zhang, P. (2011) The Recognition and Measurement of the Carbon-Assets. Journal of Accounting Research, 5, 40-42.

[4] Wan, L.W. (2010) Chinese Enterprise's Carbon Asset Management under the Background of Low Carbon Economy. Journal of Business Accounting, 17, 68-69.

[5] Kanamura, T. (2012) Comparison of Futures Pricing Models for Carbon Assets and Traditional Energy Commodities. Journal of Alternative Investments, 3, 42-44. 
[6] Warwick, P. (2012) The “Cost” of Climate Change: How Carbon Emissions Allowances Are Accounted for Amongst European Union Companies. Australian Accounting Review, 22, 54-67. http://dx.doi.org/10.1111/j.1835-2561.2011.00158.x

[7] Jiang, Y.G. and Fan, L.L. (2014) Research on the Evaluation of the Enterprise's Low-Carbon Competitiveness in the Perspective of Carbon-Intangible Assets. Journal of Business Economics, 9, 42-51.

[8] Zhao, M.J. (2003) The Enterprise’s Internal Value Network and Technical Innovation. Research Leader, 10, 15-19.

[9] Fan, L.L. (2010) The System Evaluation Method of Intangible Asset. Journal of Systems Management, 3, 305-312.

[10] Wang, Z.L. (2007) Based on the Core Competitiveness of Enterprise Intangible Asset Ability of Space Research. Southwest Jiaotong University, Chengdu.

[11] Gharaie, M. (2013) Simultaneous Optimization of $\mathrm{CO}_{2}$ Emissions Reduction Strategies for Effective Carbon Control in the Process Industries. Chemical Engineering Research and Design, 91, 1483-1498. http://dx.doi.org/10.1016/j.cherd.2013.06.006 
Scientific Research Publishing (SCIRP) is one of the largest Open Access journal publishers. It is currently publishing more than 200 open access, online, peer-reviewed journals covering a wide range of academic disciplines. SCIRP serves the worldwide academic communities and contributes to the progress and application of science with its publication.

Other selected journals from SCIRP are listed as below. Submit your manuscript to us via either submit@scirp.org or Online Submission Portal.
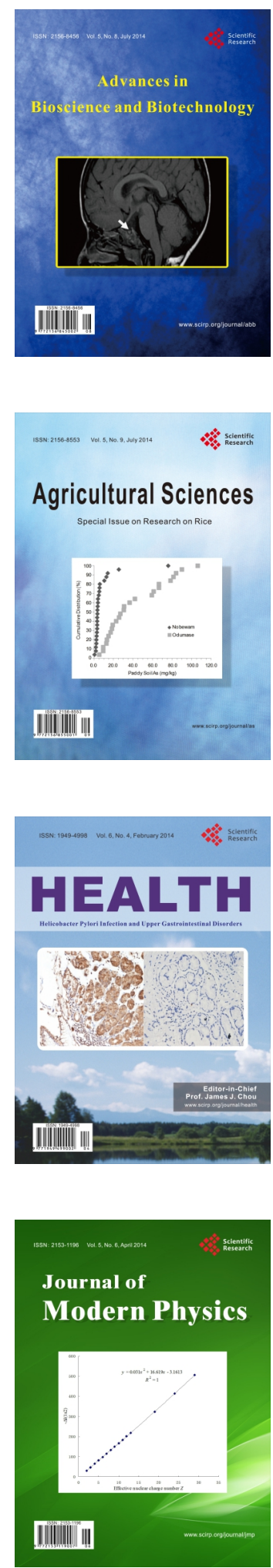
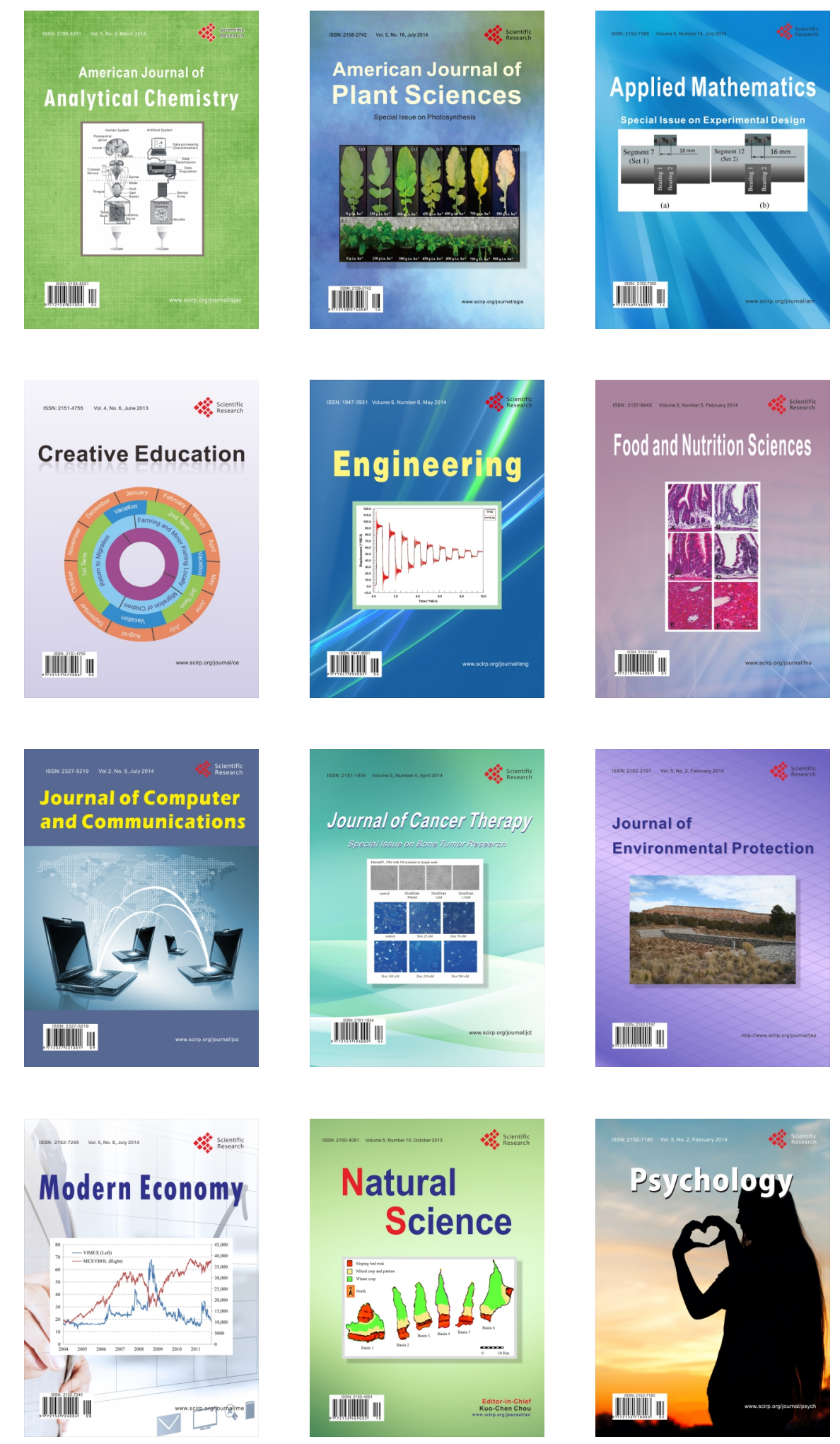